\title{
MODERN WEAPONS AND THE HUMAN EAR*
}

\author{
Major P. F. BRASHER, M.B., F.R.C.S., D.L.O., R.A.M.C. \\ British Military Hospital, Rinteln.
}

\begin{abstract}
SUMMARY :-Although there is a wide variation in sensitivity to gunfire noise, excessive exposure may lead to severe deafness, temporary initially, but repeated exposure will lead to permanent changes.
\end{abstract}

All modern weapons are potentially hazardous to hearing and this is confirmed by the high incidence of high tone deafness in combatant personnel. This type of deafness is preventable by the wearing of adequate aural protection in all noise hazardous situations.

It has long been recognised that continual exposure to high intensity noise leads to deafness, but it is only over the last few years that the true incidence of deafness in soldiers has been recognised, stimulating research and the institution of hearing conservation programmes. This has been particularly necessary due to the introduction into the Services of newer and more powerful weapons.

In the Army we are particularly concerned with impulsive noise generated by weapons of all sizes, but continuous noise produced by helicopters, troop and weaponcarrying vehicles is of no mean consequence and is potentially hazardous.

What is acoustic trauma? This is the damage inflicted on the hearing mechanism when it is exposed to high intensity noise or blast. The damage can occur both in the middle and inner ear. Middle-ear damage amounts to congestion of the tympanic membrane and middle-ear mucosa. Perforation of the tympanic membrane can occur but this is unusual and although causing discomfort heals rapidly, very rarely causing permanent damage. It is the damage incurred by the inner ear, initially temporary but eventually permanent, which is so prevalent in combatant soldiers as to be of military significance. This deafness is perceptive in nature and usually more severe for the higher frequencies. The high frequency hearing loss is due to pathological changes in the basal turn of the cochlea with loss of the outer hair cells of the Organ of Corti. It is in this region that the frequencies around $4,000 \mathrm{cps}$ are thought to be perceived. The reason for this degeneration is obscure and many theories including ischaemia, exhaustion of metabolities and mechanical stress on this region have been suggested (Chadwick, 1963, Igarshi, Schuknecht and Myers, 1964)

\section{Physical characteristics of noise generated by common service weapons}

The physical characteristics of noise generated by weapons have a direct bearing on the severity of deafness produced. When a weapon is fired there is an instantaneous change in sound pressure to peak values; this then more slowly returns to normal readings. The time for this to occur varies from weapon to weapon. When these measurements are recorded there appears to be a direct relationship between on the one hand the temporary hearing loss produced and on the other the peak sound level and duration of the impulsive noise above a hazardous level. The effects of the frequency spectrum are not clear but appear not to be directly involved (Rice and Coles, 1965).

For the conservation of hearing Rice and Coles have outlined a damage risk criterion. Unprotected exposure to pressures in excess of this criterion may render the

$\star$ As presented at the Director-General of Army Medical Services Exercise, October, 1968. 
subject liable to permanent nerve damage. The safe upper limits suggested are:-

When the duration of the main pressure pulse is under 20 msec.

$165 \mathrm{~dB}$ for single impulses.

$145 \mathrm{~dB}$ for repeated impulses.

When the duration for the main pressure pulse is between 20-200 msec.

$155 \mathrm{~dB}$ for single impulses.

$145 \mathrm{~dB}$ for repeated impulses.

For very sensitive ears a reduction of $5 \mathrm{~dB}$ may be necessary in the above values.

It can be seen from the following measurements of the physical characteristics of some modern weapons that they are all very noise hazardous (Table I) unless adequate aural protection is provided and used.

Table I

Physical characteristics of some modern weapons

\begin{tabular}{l|c|c}
\hline \multicolumn{1}{c|}{ Weapon } & $\begin{array}{c}\text { Peak sound pressure } \\
\text { level (dB) }\end{array}$ & $\begin{array}{c}\text { Time taken for peak to } \\
\text { fall by 20 dB (msec) }\end{array}$ \\
\hline 7.62 mm Self Loading Rifle (SLR) & $160-165$ & 12 \\
120 mm Mortar & $165-175$ & $>12$ \\
85 mm Carl Gustav & $187-192$ & $>12$ \\
$105 \mathrm{~mm}$ S.P. Abbott & $180-190$ & $>12$ \\
& $160-182$ & $>12$ \\
\hline
\end{tabular}

\section{Clinical aspects following exposure to gunfire}

On the range it was possible to examine soldiers immediately after exposure to gunfire and it was noted that aural pain, tinnitus and general subjective assessment were only of limited value in assessing the amount of temporary perceptive hearing loss sustained, but if tinnitus persisted after exposure it was invariably synonymous with some degree of high tone hearing loss.

Pain was not usually a predominant feature after exposure to pressures in the region of $160 \mathrm{~dB}$ as when firing the service rifle, but pressures in excess of that and particularly those generated by anti-tank guns caused considerable amounts of pain. After exposure to gunfire the tympanic membranes showed in the majority of cases capillary injection-particularly in the attic region extending down along the handle of the malleus. The soldier complaining of pain often showed ruptured capillaries and haemorrhagic bullae in the drum head. Perforation of the tympanic membrane occurred infrequently and in these cases some conductive hearing loss was apparent, but this invariably recovered completely with rapid closure of the tympanic membrane defect.

Fig. 1 shows the audiogram of an infantry sergeant who was accidently exposed without aural protection to a single round of the Carl Gustav anti-tank gun. He sustained a traumatic perforation of the left tympanic membrane with an associated deafness both conductive and perceptive in nature.

After only six weeks the tympanic membrane had healed and the conductive element of the deafness recovered, but the perceptive high tone loss remained as a permanent feature (Fig. 2). 


\section{P. F. Brasher}

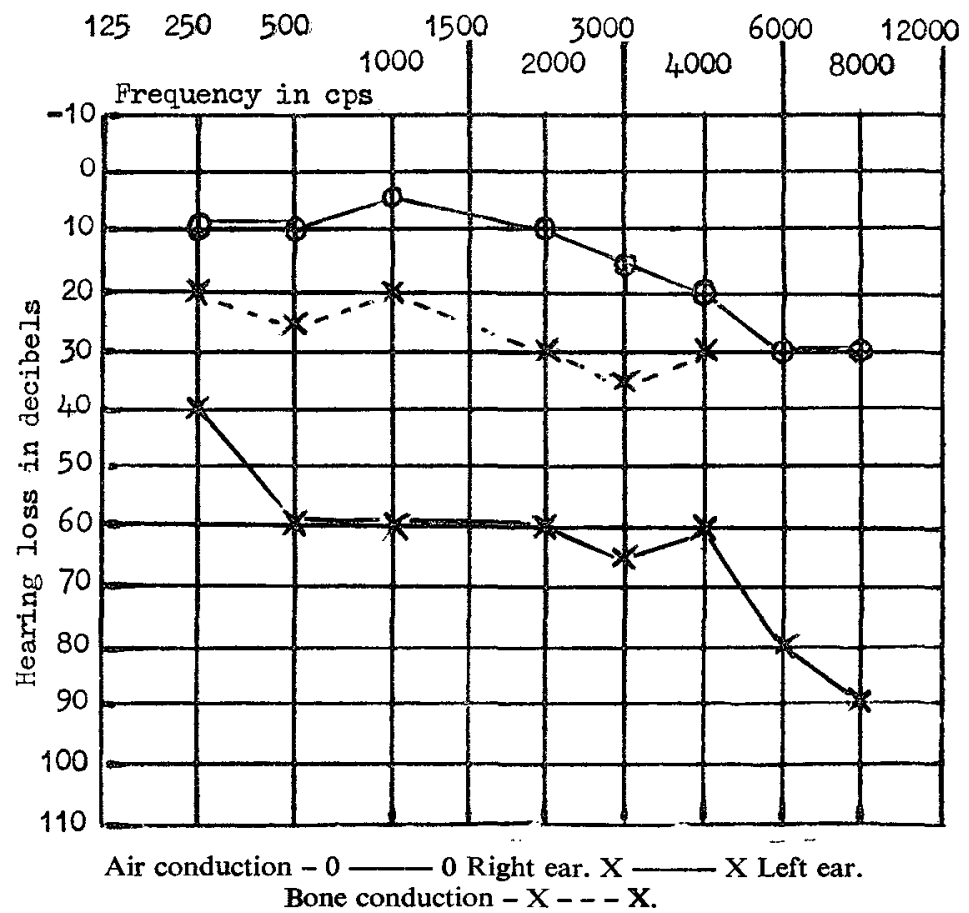

Fig. 1. Immêdiate effect of exposure to single round of Carl Gustav anti-tank gun.

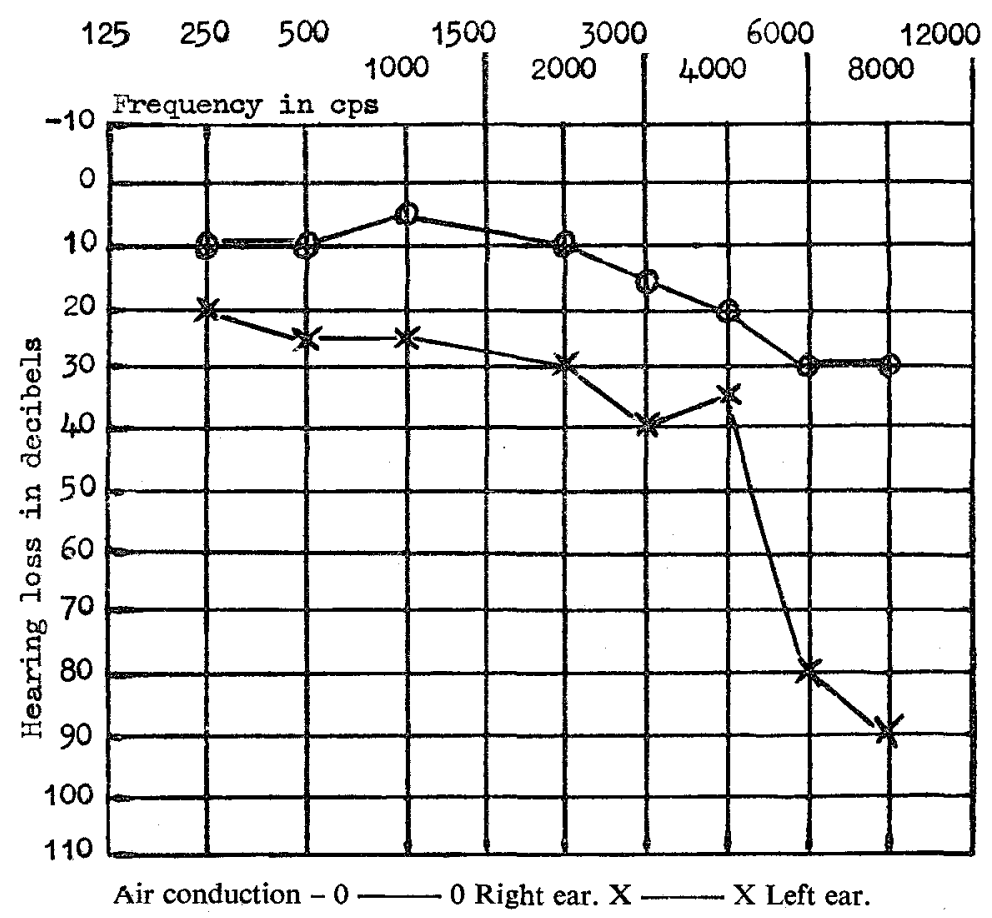

Fig. 2. Review six weeks later. 
Temporary hearing loss and recovery

It is important to understand that in the majority of cases the initial effect of gunfire on hearing is only temporary; recovery follows a log time relationship, but repeated exposure of an already damaged ear will almost certainly lead to permanent hearing loss. In a small proportion of very sensitive ears a single or very limited exposure may cause very severe hearing loss which in some cases is permanent.

Fig. 3 shows the audiogram of a young infantry soldier showing the typical high

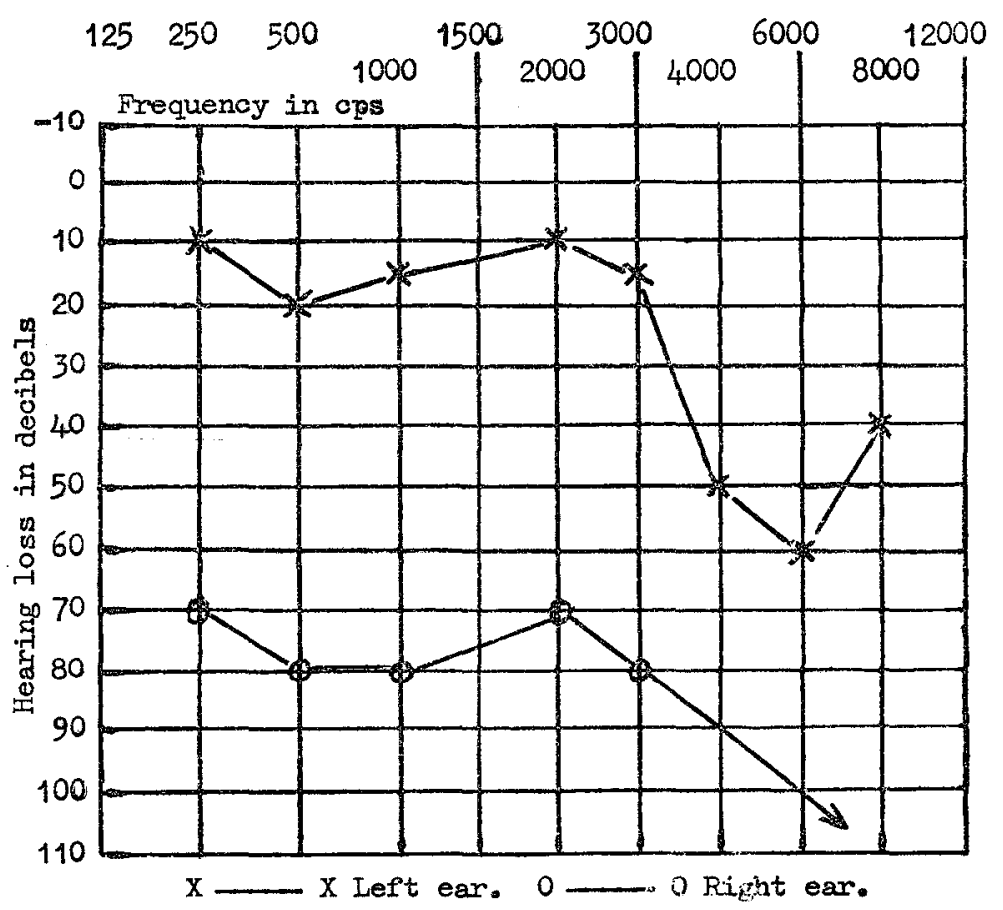

Fig. 3. Effect of exposure to five rounds of Carl Gustav anti-tank gun.

tone fall off in the left ear and almost complete permanent hearing loss in the right ear after only five rounds of unprotected exposure to the Carl Gustav anti-tank gun.

During trials at the Army Personnel Research Establishment (A.P.R.E.) which involved exposing men to varying types of impulsive noise, and monitoring the effects on their hearing by comparing pre- and post-exposure audiograms, a temporary threshold shift (TTS) criterion of $20 \mathrm{~dB}$ in any one or $15 \mathrm{~dB}$ in any two (in either ear) in the frequencies $3,4,6$, and $8 \mathrm{Kc}$ constituted sufficient grounds to merit removing the subject from the experiment until his hearing had returned to pre-exposure levels. This was necessary for, from experience, further exposure of a subject with that degree of TTS resulted in a precipitous increase in hearing loss, with a subsequent longer recovery time and the possibility of producing permanent changes. Usually subjects with peak losses of the order of $15-20 \mathrm{~dB}$ recovered in one to three hours, but greater losses were much slower to recover taking several hours or days. 
Fig. 4 shows the severe hearing loss sustained by a member of the A.P.R.E. staff

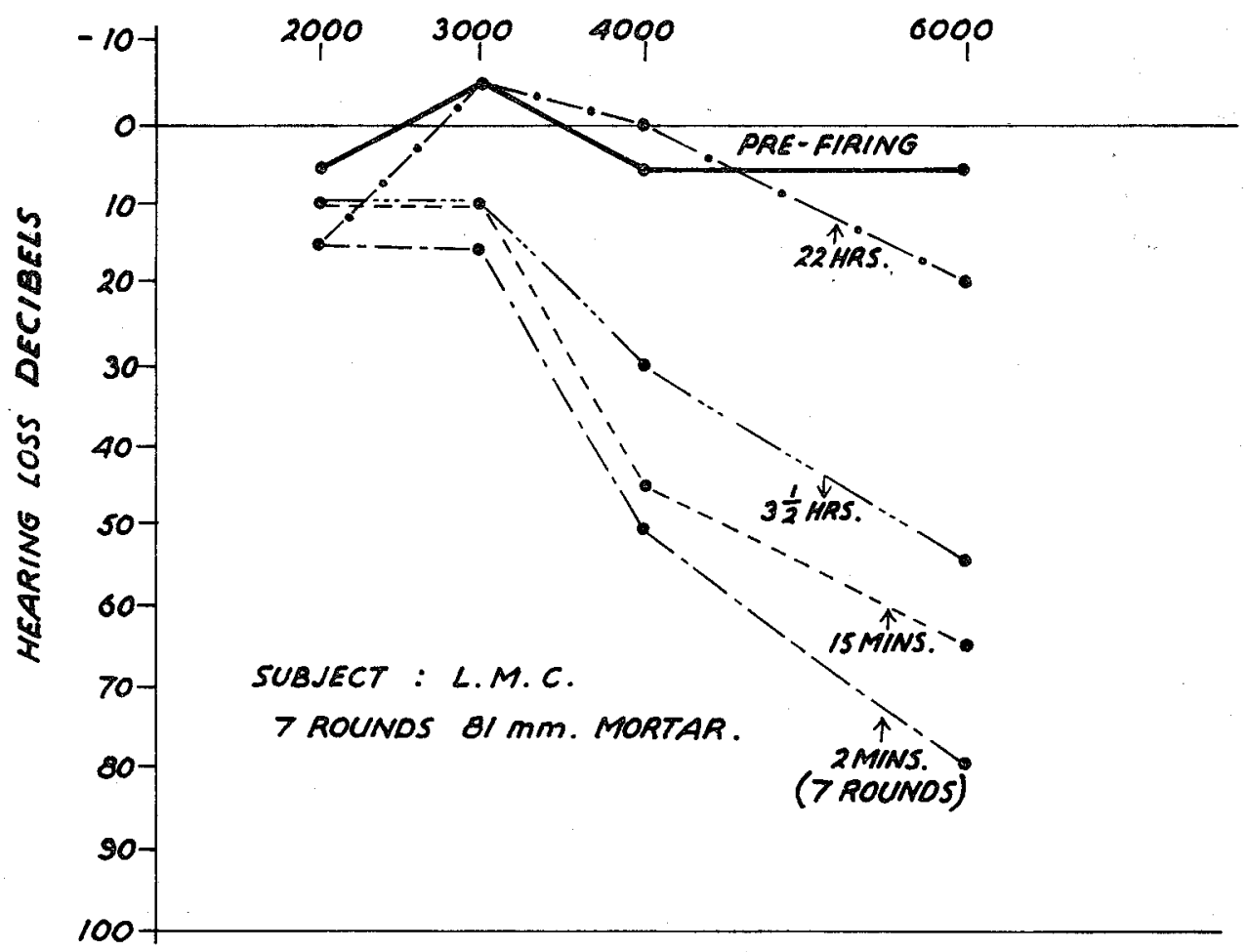

FREQUENCY CPS.

Fig. 4. Audiogram of worse ear at varying periods after exposure to $81 \mathrm{~mm}$ mortar (unprotected).

and the subsequent recovery of hearing over a 22-hour period after unprotected exposure to seven rounds of the $81 \mathrm{~mm}$ mortar.

\section{Individual sensitivity to noise}

The variations in individual sensitivity to noise both subjectively and clinically are well known. Unfortunately, as mentioned previously, aural pain, tinnitus and general subjective assessment give no indication how the individual's hearing will be affected by a given noise exposure situation.

At A.P.R.E. experiments were conducted to determine the relative sensitivity of men to impulsive noise, with the direct aim of ensuring that any form of aural protection recommended was adequate for the majority (Elwood, Brasher and Croton, Unpublished). This was done by withdrawal of subjects from a carefully selected series of noise exposures when 155 men acted as subjects for the main sensitivity test. They were examined clinically and all wax removed from the ears. Subjects with evidence of middle-ear disease and those with already existing hearing loss were excluded. The subjects' hearing was monitored before and after a maximum of three consecutive exposures of unprotected ears to impulsive noise. 
The noise source used was the SLR fired by the subject himself at a verbal command at $5 \mathrm{sec}$ intervals. The TTS criterion for withdrawing the subject from the trial was as mentioned previously.

If 20 rounds were required to reach TTS criterion, subjects placed in impulsive noise sensitivity grading I, if a further 40 rounds required, placed in sensitivity grading II, if a further 60 rounds required, placed in sensitivity grading III, and if $20+40+60$ rounds did not produce the criterion, placed in grading IV.

The results were as follows:-Grade I-26.4 per cent, Grade II-15.4 per cent, Grade III-10.9 per cent, and Grade IV-47.3 per cent.

From the above results it can be seen that about a quarter of the men were withdrawn after only 20 rounds and a further quarter after 60 or 120 rounds; the remaining 50 per cent classified as relatively resistant although further exposure would no doubt have produced hearing loss in this group.

With this very wide range of sensitivity to noise it can therefore be seen that any form of ear protection which is to be recommended for a general population must have sufficient attenuating properties to protect both the very sensitive as well as the relatively resistant.

The frequencies particularly affected in the above groups of men showing temporary hearing changes were: $-3 \mathrm{Kc}-6$ per cent, $4 \mathrm{Kc}-17$ per cent, $6 \mathrm{Kc}-45$ per cent, and $8 \mathrm{Kc}-32$ per cent.

Although it would be very desirable to exclude very sensitive subjects from occupations likely to damage hearing there is no simple or reliable test yet available. The test performed at A.P.R.E. was expensive, time-consuming and therefore impractical for large numbers of men. The wastage rate would be unacceptable in the recruiting of combatant soldiers. Even if susceptible subjects were excluded adequate ear protection would still be essential for those accepted.

\section{Acoustic reflex and its relationship to TTS}

The reasons for these variations in sensitivity to noise are obscure. The acoustic reflex (contraction of the stapedius and tensor tympani muscles in response to acoustic stimulation) modifies the conducting properties in the middle ear. The efficiency of the acoustic reflex may very well have some bearing on the variations in sensitivity to noise. The situation, however, is complicated by the fact that the latency of response of the acoustic reflex is far too long for the reflex to have any protective effect against most cases of exposure to impulsive noise, where the rise time to peak sound pressure is instantaneous. Nevertheless, it has been suggested that if the subject is forewarned as to the timing of the impulse, as would occur when he fires his own weapon, he may be able to contract his middle ear muscles in anticipation of the noise and thus possibly produce some protective effect (Reid, 1946, Coles, 1962).

This possibility was investigated (Brasher, Coles, Elwood and Ferres, 1969) by comparing variations in TTS induced by octave band noise and impulsive noise with various measures of the acoustic reflex in 16 soldiers with normal hearing. The results showed that the varıations in the acoustic reflex mechanism did not bear any relationship to individual susceptibility either to impulsive or prolonged continuous noise. The ability to contract the middle ear muscles in anticipation of the noise had no relationship to susceptibility to impulsive noise hearing loss. 


\section{Permanent noise-induced deafness}

The onset of permanent deafness and its relationship to temporary changes is not clear. In all our experiments at A.P.R.E. the subjects' hearing was not allowed intentionally to fall by more than $20 \mathrm{~dB}$ in any one or $15 \mathrm{~dB}$ in any two of the frequencies tested and full recovery was necessary before being exposed again. In practice, however, temporary hearing losses far in excess of these criteria are allowed to occur and the ear repeatedly exposed before recovery begins. Repetition of insults on an already temporarily damaged ear is almost certainly the main reason for the onset of permanent nerve damage.

The incidence of permanent changes in hearing are well described by Livesey (1965) who in a survey of 100 randomly selected infantry men, who had never previously sought advice reference their hearing, found 54 cases of perceptive high tone deafness assumed to be due to acoustic trauma. Of the 200 ears examined he found evidence of damage in 93. He classified hearing loss in the frequencies 3,4 and $6 \mathrm{Kc}$ into four groups:-Group I-those with hearing loss up to $30 \mathrm{~dB}$, Group II-those with hearing loss between 31-50 dB, Group III-those with hearing loss between 51-70 dB, and Group IVthose with hearing loss over $70 \mathrm{~dB}$.

In a similar survey A.P.R.E. were able to substantiate Livesey's figures, performing pure tone audiometry on 117 infantry, artillery and armoured corps personnel who had not previously complained of ear trouble or deafness.

In the first two categories (Table II) a 30 per cent incidence of hearing loss greater

Table II

Percentage incidence of permanent hearing loss in service personnel

\begin{tabular}{l|c|c|c}
\hline \multicolumn{1}{c|}{$\begin{array}{c}\text { Livesey's classification of } \\
\text { hearing loss }\end{array}$} & $\begin{array}{c}\text { Livesey's 100 } \\
\text { infantry men }\end{array}$ & $\begin{array}{c}\text { A.P.R.E. 117 } \\
\text { combatant } \\
\text { personnel } \\
\%\end{array}$ & $\begin{array}{c}100 \text { R.A.M.C. } \\
\text { personnel } \\
\%\end{array}$ \\
\hline Group I & 24 & 36 & 21 \\
Group II & $\%$ & 16 & 6 \\
Group III & 11 & 10 & 1 \\
\hline
\end{tabular}

than $30 \mathrm{~dB}$ in one or more of the frequencies tested is shown. The ages of the men ranged between 19 and 38 years with an average of 22 years. The survey covered the full range of rank structure including officers.

When these figures are compared with the hearing of 100 R.A.M.C. personnel with a similar age, rank and length of service distribution, but who had been exposed only infrequently to gunfire noise the difference is obvious.

\section{Military significance of deafness following gunfire.}

In order to realise the significance of the above hearing losses it is important to appreciate that a loss of $30 \mathrm{~dB}$ at any of the higher frequencies means that a tone in these frequencies which is just heard by a normal ear has to be raised by $30 \mathrm{~dB}$ in order to be heard by a deafened ear (Murray and Reid, 1946).

Threshold hearing is of great importance to sentries whose ability to detect even 
the faintest sounds may mean the difference between life and death for themselves and their colleagues. This is particularly significant, as personnel sounds, for example, cracking of twigs, rustle of leaves, contain many high frequency components and it is these which are particularly affected by gunfire. Localization of sound is also made difficult as one ear is very often affected more than the other.

It can be seen, therefore, that in many of the men tested their efficiency as sentries is extremely low, some temporarily, others permanently.

If the damage to the higher frequencies is slight the soldier may have little difficulty in hearing normal conversations, as can be seen by the number of men who did not realise they had some hearing deficiency until tested audiometrically. This is because the frequency components of speech lie particularly between $250-2000 \mathrm{cps}$, not immediately affected by gunfire, but repeated exposure may very well cause extension of the damage to involve those frequencies affecting the soldier's ability to understand words of command. The significance of this needs no further elaboration.

\section{Aural Protection}

The relative merits of the various types of ear protectors vary considerably as can be seen from Fig. 5 (Croton and Dennis, 1965).

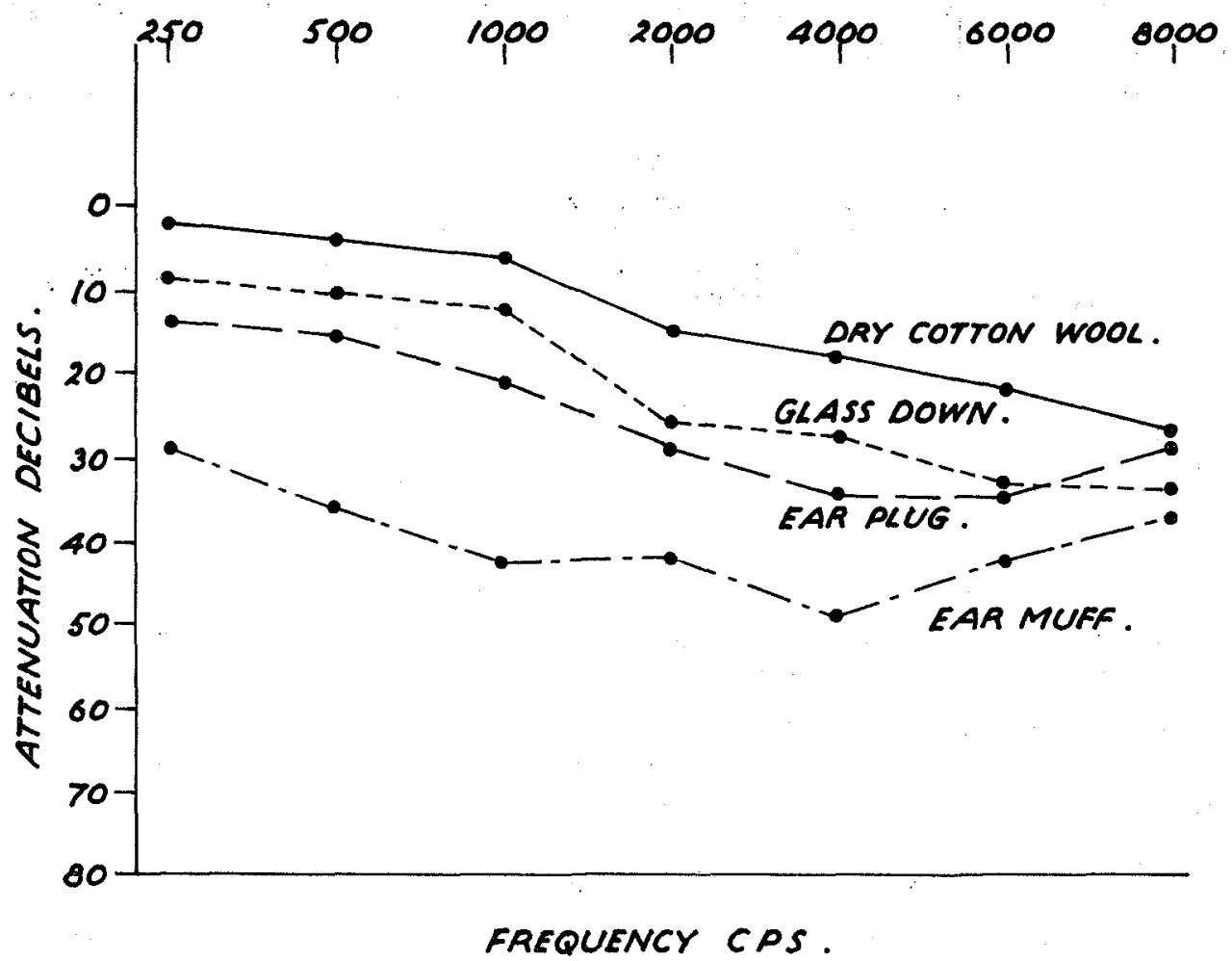

Fig. 5. Noise attenuation provided by various types of aural protection.

Despite the poor attenuation of dry cotton wool, making it virtually useless as an aural protector, it is still widely used, giving a false sense of security to the wearer. 
Cotton wool with vaseline, long recommended, is efficient but messy and invariably the vaseline is omitted. This has been superseded by the V.51.R. plastic ear plug. This gives very adequate protection if well fitted in most noise exposure situations, but for gunnery instructors who are exposed continually to high intensity noise greater protection may be necessary. This can be achieved by using the ear muff type of protector but as yet this is not generally provided. But no matter how good the plug or muffs, if men cannot be encouraged or persuaded to wear them the incidence of deafness will not decrease.

Unfortunately the ear plugs are slightly uncomfortable and time-consuming in fitting and there is the undeniable problem of vocal communication when they are in use. There does not appear at this moment to be a simple solution to this major drawback. Nonetheless, there are many noise exposure situations such as fixed range work where ear plugs can be worn safely and effectively. The choice lies between a $30 \mathrm{~dB}$ attenuation of hearing due to ear plugs which can be relieved immediately and overcome by a loud hailer in training, or a $30 \mathrm{~dB}$ or greater loss in hearing from unprotected exposure which may take several hours or days to recover and in 30 per cent of cases leaves some significant permanent deafness. Men should be convinced that the care of their ears is as equally important as the care of their guns and that the wearing of ear plugs is not sissy or effeminate.

Finally, there is the problem of what to do with these permanently deafened soldiers. Automatic downgrading of any but severely deafened men (Grade IV of Livesey's classification) would result in an unacceptable loss of men from teeth arms.

The very easy solution of excluding combatant soldiers from exposure to gunfire which would certainly prevent further deterioration in hearing is, for the individual, a catastroph ending any hope of promotion and a useful career. Change of Arm of Service is for the majority either impractical or non-acceptable. If the soldier is downgraded and excluded from the guns he is given unsatisfactory jobs around the unit with loss of morale and ultimately his premature departure from the Service. Every case, therefore, must be assessed on its merits, taking into account the soldier's training, promotion prospects and attitude to the Army.

What must be impressed on these slightly deafened soldiers is the importance of wearing satisfactory ear protection whenever they are exposed to high intensity noise in order to prevent further deterioration in their hearing.

\section{REFERENCES}

Chadwick, D. L. (1963). Practitioner 191, 733 and J. Laryng. 77, 467.

Brasher, P. F., Coles, R. R. A., Elwood, M. A. and Ferres, H. M. (1969). J. roy. Army med. Cps. Vol. 115, 172.

Coles, R. R. A. (1962). Contributed Paper H.21. 4th International Congress on Acoustics, Copenhagen. Croton, L. M. and DenNis, J. P. (1965). J. Sci. Tech. 11. 4, 178.

Elwood, M. A., Brasher, P. F. and Croton, L. M. (Unpublished). Summarised by Elwood, M. A. (1967). Proc. roy. Soc. Med. 80, 1124.

Igarshi, M., Schuknecht, H. F. and MYers, E. (1964). J. Laryng. 78, 115.

LIVESEY, B. (1965). J. roy. Army med. Cps. 111, 188.

Murray, N. E. and ReID, G. (1946). J. Laryng. 60, 118.

REID, G. (1946). J. Laryng. 61, 109.

RICE, C. G. and Coles, R. R. A. (1965). Proc. 5th. int. Congr. Accoustics (Liège). Ed. D. E. Commins. 